\title{
$\begin{array}{lllllllll}\text { I } & N & S & T & \text { I } & T & \text { U } & T & E\end{array}$
}

\section{Lack of Protections for Home Care Workers Overtime Pay and Minimum Wage}

$\mathrm{T}$ The large scale movement of women into the paid labor market has brought sweeping change to the structure of family life and who cares for family members. One consequence of this phenomenon was the development of a category of paid workers - the home care worker - to provide care that had previously been performed by women in the home. Today, our society depends, in part, on the caring labor of many paid professionals to supplement the unpaid family care of the elderly and disabled adults. As baby boomers enter retirement and the need for care at home rises even more, the demand for a skilled and stable paid home care workforce is stronger than ever. In fact, the Bureau of Labor Statistics projects that the home care workforce will grow from 1.7 million to 2.6 million by 2018 , making it one of the fastest growing occupations in America. ${ }^{1}$

Home care workers (home health aides and personal care aides combined) make up more than half of the paid direct care workforce (see Figure 1). ${ }^{2}$ These aides assist clients in their homes with personal and household duties such as bathing, dressing, shopping, cleaning, and meal preparation, as well as routine healthcare such as changing bandages and dressing wounds. ${ }^{3}$ Some also help clients by performing simple medical tasks such as administering medication and checking temperatures. Hospital aides, nursing home aides, and home care aides engage in similar work for their clients, even though they work in different institutional settings. Yet, home health aides and personal care aides have higher poverty rates (20 percent and 28 percent, respectively) than hospital aides and nursing home aides (about 12 percent for both). In addition, they typically work fewer hours per week, have lower rates of health insurance coverage, rely on public assistance to a greater extent, and receive lower hourly wages. ${ }^{4}$

One underlying factor involved in the lower hourly wages paid to home care workers is that they are not covered under the Fair Labor Standards Act of 1938 (FLSA). The FLSA created basic wage protections for workers, including a minimum wage and overtime pay, and the intent was to address "starvation wages and intolerable hours." ${ }^{5}$ In 1974, the FLSA was amended to include "domestic service"

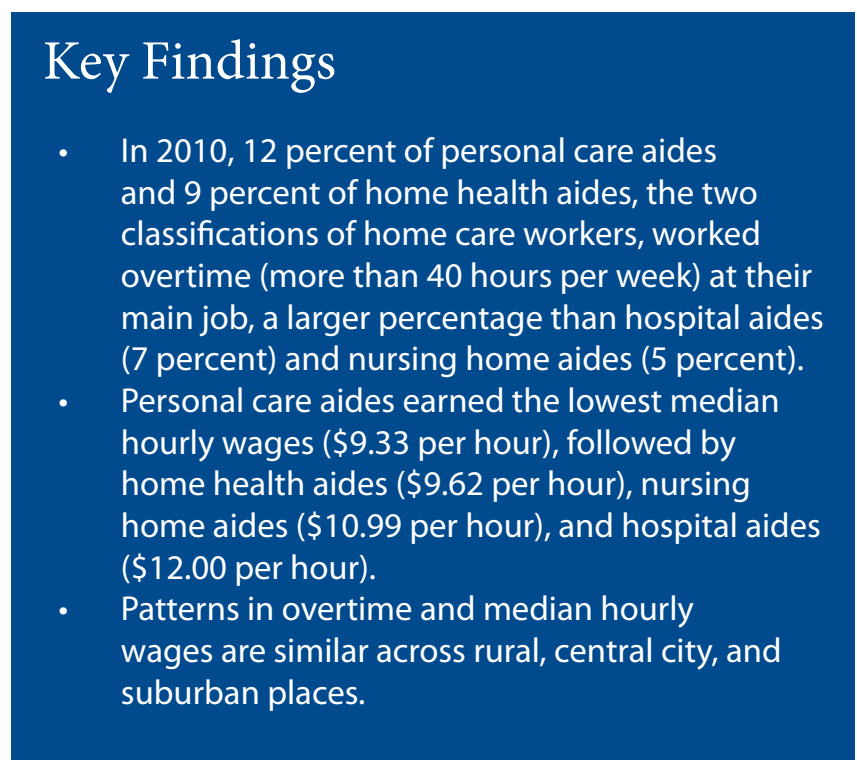

Figure 1. Percent distribution of Direct CARe

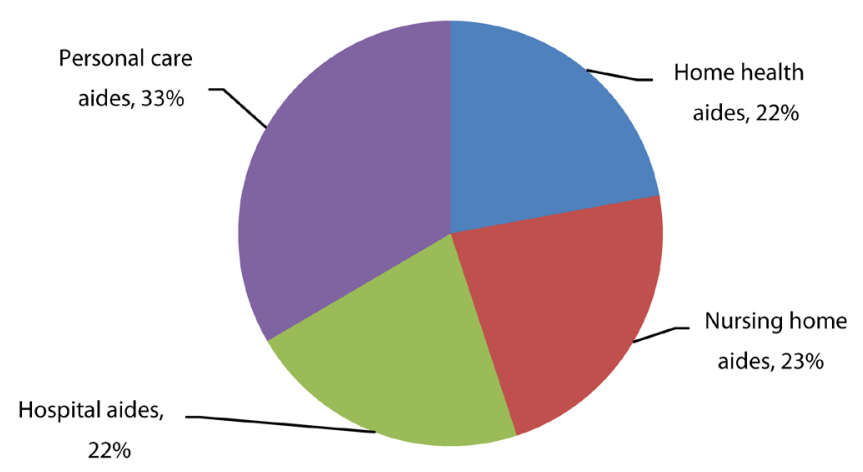

Source: 2011 CPS Annual Social and Economic Supplement

UNIVERSITY of NEW HAMPSHIRE 
workers employed in private households working, for example, as cooks, butlers, valets, maids, housekeepers, governesses, janitors, laundresses, caretakers, handymen, gardeners, and family chauffeurs. ${ }^{6}$ The 1974 amendment also created an exemption from minimum wage and overtime pay for one segment of domestic service employees-those employed "to provide companionship services for individuals who (because of age or infirmity) are unable to care for themselves..."7 This companionship exemption included paid workers employed by third-party agencies. The intent of Congress was not to deny coverage to employees whose "vocation" was domestic service, but rather to exempt casual babysitters and companions who were not regular breadwinners or responsible for their families' economic support. ${ }^{8}$ Yet in reality, home care workers' wages support families with children, often as sole breadwinners. ${ }^{9}$

In December 2011, the Department of Labor issued proposed rule changes to the FLSA that would narrow the companionship exemption so that most home care workers would no longer be exempt from overtime pay and minimum wage requirements. ${ }^{10}$ The home care workforce has changed substantially since the 1974 companionship exemption was put into place, a time when fewer elderly and disabled adults required paid care to remain in their homes when they needed medical assistance or help with daily activities. ${ }^{11}$ Today, it is a growing and critical part of the adult care industry, with official counts at 1.7 million paid workers assisting clients in their homes. ${ }^{12}$ Others estimate the workforce to be closer to 2.3 million. ${ }^{13}$

The FLSA companionship exemption has led to substandard working conditions in the form of suppressed wages and long work hours among some of the home care workforce, contributing to difficulty in retaining and recruiting workers to this field. Low wages have been shown to contribute to the high level of turnover and impede efforts to improve quality of care among the direct care workforce, including home care aides. ${ }^{14}$ Thus, providing basic wage protection to home care aides is likely to improve job quality and make it easier to attract and maintain workers. This brief examines overtime hours and hourly wages among home health aides and personal care aides (many of whom are not currently covered by the FLSA), and compares them with hospital aides and nursing home aides, a group that is typically covered by the FLSA.

\section{Overtime and Part-Time Hours}

On average, in 2010 paid direct care workers spent 34 hours per week working at their main job, fewer hours per week than the typical U.S. worker spent working (38 hours per week).$^{15}$ Home health aides and personal care aides worked fewer hours per week than hospital aides and nursing home aides (on average 33 hours per week among both groups of home care aides compared with 35 hours per week and 36 hours per week among hospital aides and nursing home aides, respectively).

Overtime is relatively uncommon among the direct care workforce, with about 9 percent of these workers reporting more than 40 hours worked per week (see Figure 2). In 2010, 12 percent of personal care aides and 9 percent of home health aides worked overtime (more than 40 hours per week), a larger percentage than hospital aides (7 percent) and nursing home aides (5 percent). This discrepancy may be due to the exemption status of personal care aides and home health aides under the FLSA, which denies overtime pay for home care aides, but requires it for hospital aides and nursing home aides. Due to this requirement, hospitals and nursing homes may curtail overtime. The lack of required overtime pay for home care workers may be one of the factors encouraging the use of high-hours staffing for clients who need around-the-clock care. ${ }^{16}$ But research shows that long work hours may contribute to work-related injuries, undermine the quality of care, and increase turnover, which is costly for the employer. ${ }^{17}$ Overtime among home care aides is similar in rural, suburban, and central city areas.

Figure 2. Distribution OF AVERAGE WEEKLY HOURS WORKED AT MAIN JOB, 2010

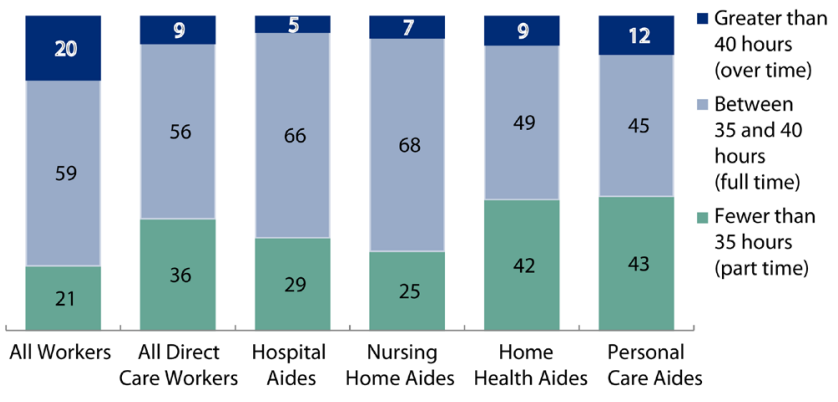

Source: 2011 CPS Annual Social and Economic Supplement 
Another important feature of direct care employment is the prevalence of part-time hours, particularly among home health aides and personal care aides. ${ }^{18}$ A large proportion, more than 40 percent, of home health aides and personal care aides work fewer than 35 hours per week. Part-time work is less common among hospital aides (30 percent) and nursing home aides (25 percent).

The majority of part-time workers work part time for voluntary reasons. However, involuntary part-time work for reasons such as slack work or business conditions, or situations where workers can only find part-time or seasonal work, indicate underemployment or an unmet need for more work hours. Involuntary part-time work is more common among home health aides and personal care aides than among hospital aides and nursing home aides (see Figure 3). It is likely that some of the increased costs projected to arise from requiring overtime pay for home care aides could be avoided by redistributing work hours to those who indicate a desire for more work hours. Curtailing underemployment could also decrease turnover, as workers who want more hours may leave in search of full-time options.

Figure 3. PERCENT WORKING PART TIME For

INVOLUNTARY REASONS, 2010

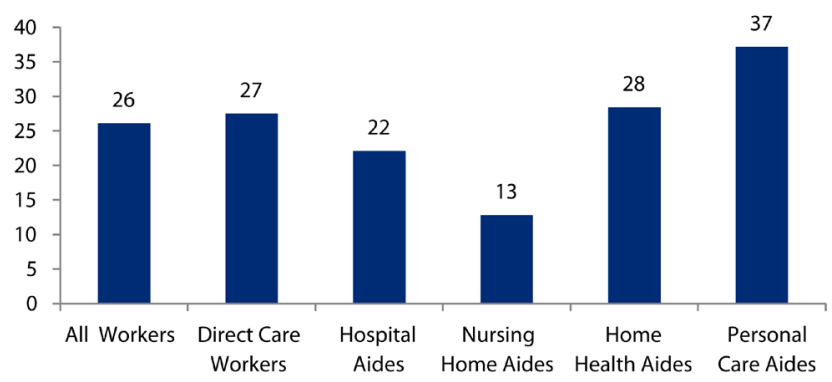

Source: 2011 CPS Annual Social and Economic Supplement

\section{Hourly Wages}

Currently the Federal minimum wage is $\$ 7.25$ per hour. Figure 4 shows there is a clear hierarchy in wages between the different types of direct care workers, with hospital aides earning the highest median hourly wages ( $\$ 12.00$ per hour), followed by nursing home aides (\$10.99), home health aides (\$9.62), and personal care aides (\$9.33). This same hierarchy is maintained across place, but wages are lowest in rural areas and highest in the suburbs (see Table 1). These hourly rates are often for direct care hours only, as workers typically are not paid for travel time between clients or reimbursed for travel costs, which lowers their real hourly wages.
Yet, median wages mask the fact that some workers are paid lower than the minimum wage. The median hourly wage of $\$ 9.33$ paid to personal care aides means that half of these workers receive a wage above $\$ 9.33$, and half receive a wage below it. Another measure of wages is to look at the wage paid to those who are in the lowest quartile of wages, or the wage paid to the lowest quarter of workers. Figure 4 shows that one quarter of personal care aides earn less than $\$ 6.59$ per hour (the lowest quartile hourly wage), and one quarter of home health aides earn less than $\$ 7.21$ per hour, while hospital aides and nursing home aides had higher quartile hourly wages. Again, this discrepancy is likely due in part to the exemption status of personal care aides and home health aides that denies them minimum wage protection under the FLSA. The same pattern is seen across place, with personal care aides and home health aides having lower quartile hourly wages compared with hospital aides and nursing home aides (see Table 1).

Figure 4. MEdian AND LOWEST QUARTILE HOURLY WAGES, 2010

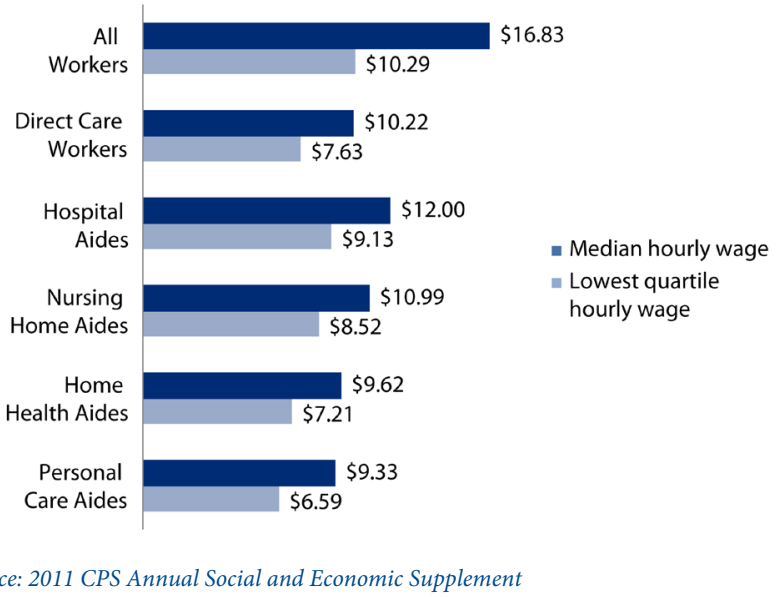

TABLE 1. MEDIAN AND LOWEST QUARTILE HOURLY WAGES BY PLACE, 2010

\begin{tabular}{|c|c|c|c|c|c|c|}
\hline & $\begin{array}{c}\text { All } \\
\text { Workers }\end{array}$ & $\begin{array}{c}\text { Direct } \\
\text { Care } \\
\text { Workers } \\
\end{array}$ & $\begin{array}{c}\text { Hospital } \\
\text { Aides }\end{array}$ & $\begin{array}{c}\text { Nursing } \\
\text { Home } \\
\text { Aides } \\
\end{array}$ & $\begin{array}{l}\text { Home } \\
\text { Health } \\
\text { Aides }\end{array}$ & $\begin{array}{c}\text { Personal } \\
\text { Care } \\
\text { Aides } \\
\end{array}$ \\
\hline \multicolumn{7}{|l|}{ Rural } \\
\hline Median hourly wage & $\$ 14.42$ & $\$ 9.62$ & $\$ 10.42$ & $\$ 10.12$ & $\$ 8.75$ & $\$ 8.65$ \\
\hline Lowest quartile hourly wage & $\$ 9.58$ & $\$ 6.73$ & $\$ 8.17$ & $\$ 7.69$ & $\$ 6.32$ & $\$ 6.00$ \\
\hline \multicolumn{7}{|l|}{ Central City } \\
\hline Median hourly wage & $\$ 16.83$ & $\$ 10.26$ & $\$ 11.22$ & $\$ 11.09$ & $\$ 9.62$ & $\$ 9.44$ \\
\hline Lowest quartile hourly wage & $\$ 10.10$ & $\$ 7.69$ & $\$ 8.97$ & $\$ 8.65$ & $\$ 7.69$ & $\$ 6.82$ \\
\hline \multicolumn{7}{|l|}{ Suburban } \\
\hline Median hourly wage & $\$ 18.33$ & $\$ 11.50$ & $\$ 14.42$ & $\$ 12.02$ & $\$ 11.06$ & $\$ 9.62$ \\
\hline Lowest quartile hourly wage & $\$ 11.11$ & $\$ 8.46$ & $\$ 10.00$ & $\$ 9.62$ & $\$ 7.69$ & $\$ 7.21$ \\
\hline
\end{tabular}

Source: 2011 CPS Annual Social and Economic Supplement 


\section{Conclusion}

Narrowing the companionship exemption to cover home care workers employed by third-party agencies will increase costs. The Department of Labor projects that the average annualized cost of the rule change will total about $\$ 4.7$ million per year over ten years. ${ }^{19}$ Opponents of the rule change fear that states and employers will be forced to cut care for adults and persons with disabilities in order to pay home care aides the minimum wage and overtime pay. They also point out that travel time between clients and overtime pay are generally not reimbursed by Medicaid and Medicare-the largest funder of the cost for providing home care services..$^{20}$ Ironically, the Medicaid program views the work of home care workers not as companionship since they do not reimburse for simple companionship or custodial observation, but rather for assistance that is necessary and directly related to activities of daily living, i.e., personal care services. ${ }^{21}$

Several states already mandate employers of home care workers to meet labor standards and pay overtime and minimum wages. ${ }^{22}$ Experience in these states suggests that the costs to employers can be managed through improved scheduling and management of overtime usage. For example, in New York City, Cooperative Home Care Associates-an agency that pays workers a premium overtime rate-limited overtime to less than 10 percent of all hours through the use of a tracking system. ${ }^{23}$ And in Illinois, Community Care Systems, Inc. reduced its overtime costs when the state required minimum wage and overtime pay for home care workers by more evenly distributing hours among workers and carefully tracking worker time.

Since the high incidence of involuntary part-time work among the home care workforce demonstrates a demand for more work hours, reassigning work loads could facilitate the minimization of overtime pay. These examples can provide a blueprint for efficient ways to transition to the FLSA standards.

The data in this brief suggest that narrowing the companionship exemption would benefit workers by raising their wages, improving the quality of care for clients, and reducing turnover. Increased wages-even just to the minimum wage-among the home care workforce could help reduce poverty (and reliance on public assistance), as well as child poverty since many home care workers' wages support families with children. Narrowing the companionship exemption could also help the nation's economy by improving job quality, stabilizing the home care workforce, and encouraging new workers to enter the profession.

\section{Data Used}

This brief uses data from the 2011 U.S. Census Bureau's Current Population Survey (CPS) Annual Social and Economic Supplements (ASEC). The CPS provides a nationally representative sample of households and the individuals in those households, and collects demographic, economic, and employment information. The CPS is a widely used source of data on labor force issues in the United States, and provides official government statistics on employment, poverty, and health insurance coverage.

Following the methodology developed by Candace Howes and Kristin Smith for Chapter 4, "Paid Care," in For Love and Money: Care Provision in the U.S. (edited by Nancy Folbre and forthcoming in 2012), the direct care workforce is identified based on both occupation and industry variables in the CPS for the longest job held in the previous year, or in 2010. By including both occupation and industry in the definition we can exclude occupations or industries that are not generally considered part of the direct care workforce (such as health aides that work in manufacturing plants), and assign more distinct classifications of care workers than the occupational grouping alone allow. See Howes, Candace, Carrie Leana, and Kristin Smith, Chapter 4, "Paid Care" for more details on this methodology.

Hours worked are the usual hours worked per week in 2010 among paid workers working at one job only. The hours worked variable collects usual hours worked at all jobs, thus by selecting only workers with one job we eliminate the possibility of overtime hours due to multiple jobs. Results (not shown) are similar between those who work at one job and those who work at multiple jobs, as only approximately 10 percent of direct care workers hold more than one job. The analysis of reasons for voluntary and involuntary part-time work are computed using the variable PRPTREA, based on Bureau of Labor Statistics definitions for economic (involuntary) and noneconomic (voluntary) reasons presented in "Table 20: Persons at work 1 to 34 hours in all and in nonagricultural industries by reason for working less than 35 hours and usual full- or part-time status," found at http://bls.gov/cps/cpsaat20.pdf. Median hourly wages are calculated using the total annual earnings divided by the annual hours worked in the same year (usual hours worked per week multiplied by the number of weeks worked in the year). The median hourly wage estimates produced by this methodology are very similar to the official statistics published by the Bureau of Labor Statistics, found at http://www.bls.gov/oes/current/ oes_stru.htm\#31-000.

The term "rural" here refers to persons living outside the officially designated metropolitan areas. "Urban" refers to persons living within metropolitan areas.

For more information on official definitions, see Office of Management and Budget, OMB Bulletin No. 60-01 (December 5, 2005), available at http://www.whitehouse.gov/omb/ bulletins/fy2006/b06-01_rev_2.pdf.

Comparisons presented in the text are statistically significant at the 0.05 level. 


\section{E N D N O TES}

1. See Bureau of Labor Statistics, Employment Projections, Table 1.3 Fastest Growing Occupations, available at http:// www.bls.gov/emp/ep_table_103.htm.

2. Two major occupational categories-personal care aides and home health aides-when combined together and caring for clients in the home are commonly referred to as home care workers or home care aides. My estimates differ somewhat from the Bureau of Labor Statistics, Occupational Employment Statistics (OES) estimates because 1) the OES data are based on surveys of establishments and thus exclude home care workers employed by private households or the self-employed; 2) the OES data include in their home health aide occupation those working in institutions such as nursing homes; and 3) the occupation and industry codes in the OES and the Current Population Survey (CPS) are similar but not identical. Following the methodology developed by Candace Howes and Kristin Smith for Chapter 4, "Paid Care," in For Love and Money: Care Provision in the U.S. (edited by Nancy Folbre and forthcoming in 2012), the direct care workforce is split into four mutually exclusive categories of workers (personal care aides, home health aides, nursing home aides, and hospital aides) based on both occupation and industry variables in the CPS. We believe this methodology presents a more accurate and comprehensive picture of the direct care workforce. For example, workers with the occupation "Nursing, psychiatric and home health aides (3600)" and the industry "Nursing Care Facilities (8270)" are classified in this brief as nursing home aides.

3. U.S. Bureau of Labor Statistics, Occupational Employment Statistics program, available at http://www.bls.gov/oes/current/oes_stru.htm\#31-0000.

4. Data not shown but available upon request, but see Kristin Smith and Reagan Baughman, "Caring for America's Aging Population: A Profile of the Direct-care Workforce," Monthly Labor Review, 130 (9) (2007): 20-25; and Candace Howes, Carrie Leana, and Kristin Smith, "Chapter 4, Paid Care" in For Love and Money: Care Provision in the U.S., edited by Nancy Folbre (New York: Russell Sage Foundation, forthcoming 2012).

5. Jonathan Grossman, Fair Labor Standards Act of 1938: Maximum Struggle for Minimum Wage, 1978, available at http://www.dol.gov/oasam/programs/history/flsa1938.htm\#.

6. Department of Labor, Wage and Hour Division, "Proposed Rules. Application of the Fair Labor Standards Act to Domestic Service," Federal Register, 76, No. 248 (2012), available at http://www.regulations.gov/\#!documentDetail;D=W HD-2011-0003-0001.

7. Ibid

8. Ibid.
9. Smith and Baughman, "Caring for America's Aging Population"; Paul Sonn, Catherine Ruckelshaus, and Sarah Leberstein, Fair Pay for Home Care Workers: Reforming the U.S. Department of Labor's Companionship Regulations Under the Fair Labor Standards Act (Washington, DC: National Employment Law Project, 2011).

10. The proposed rule change applies to home care workers employed by third parties (e.g., home care agencies), but leaves the possibility for continued exemption of minimum wage and overtime pay for those employed directly by families, as long as work other than companionship (or "incidental" work) does not exceed 20 percent.

11. For a more full description of the history of the Fair Labor Standards Act companionship exemption, see Lisa Forhan, "Minimum Wage and Overtime Protection for All? A Closer Look at the Companionship Exemption, Policy Brief No. 6 (New York: Direct Care Alliance, 2010); and the Department of Labor, Wage and Hour Division, "Proposed Rules."

12. U.S. Bureau of Labor Statistics, Occupational Employment Statistics program.

13. New numbers released by PHI include official numbers of home health aides and personal care aides, as well estimates of aides employed directly by consumers under publicly-financed programs and estimates of the "grey market," aides thought to work directly for families and individuals under private agreements. See Dorie Seavey and Abby Marquand, "Caring in America: A Comprehensive Analysis of the Nation's Fastest-Growing Jobs: Home Health and Personal Care Aides, (New York: PHI, 2011).

14. Smith and Baughman, "Caring for America's Aging Population"; Diane Brannon et al., "Job Perceptions and Intent to Leave Among Direct Care Workers: Evidence From the Better Jobs, Better Care Demonstrations," The Gerontologist, Col 47, No. 6 (2007) :820-829; and R. Baughman and K. Smith, "Medicaid Wage pass-Throughs and Compensation for Providers of Long-Term Care," Medical Care, 48 (2010): 426-432.

15. Hours and wage data are shown for workers age 16 and over at their main job among those with only one job. We exclude the 10 percent of workers with multiple jobs to avoid the possibility of overtime hours due to multiple jobs.

16. Sonn, Ruckelshaus, and Leberstein, Fair Pay for Home Care Workers.

17. Howes Candace, "Living Wages and Retention of Homecare Workers in San Francisco," Industrial Relations, 44 (2005); S. Keller, "Effects of extended work shifts and shift work on patient safety, productivity, and employee health," American Association of Occupational Health Nurses Journal, 
57(12): 497-502 (2009); C. Caruso et al., "Overtime and extended work shifts: Recent findings on illnesses, injuries, and health behaviors" (Cincinnati, OH: National Institute for Occupational Safety and Health, U.S. Department of Health and Human Services, April 2004); and A. Dembe et al., "The impact of overtime and long work hours on occupational injuries and illnesses: New evidence from the United States," Occupational and Environmental Medicine, 2005, 62: 588597; C.P. Ladrigan et al., "Effect of Reducing Intern's Weekly Work Hours on Sleep and Attentional Failures," New England Journal of Medicine 351 (2004): 1838-1848.

18. Although seemingly incongruous, home care workers can simultaneously be more likely to work overtime hours and work fewer hours on average per week than hospital aides and nursing home aides because of the large proportion of home care workers working part-time hours.

19. Department of Labor, Wage and Hour Division, "Proposed Rules."

20. Ibid.

21. U.S. Department of Health \& Human Services, Office of the Assistant Secretary for Planning \& Evaluation, "Understanding Medicaid Home and Community Services: A Primer," November 2000, 61, available at http://aspe.hhs.gov/ daltcp/reports/primer.pdf.

22. Fourteen states have statutes providing minimum wage and overtime protections to all or most third-party home care employees (Colorado, Hawaii, Illinois, Maryland, Massachusetts, Michigan, Minnesota, Montana, Nevada, New Jersey, New York, Pennsylvania, Washington, and Wisconsin). Maine and California extend minimum wage and overtime protection for home care workers employed by for-profit agencies. Arizona, Nebraska, North Dakota, Ohio, South Dakota, and the District of Columbia provide minimum wage protection to home care workers employed by third parties, but not overtime protection. See Sonn, Ruckelshaus, and Leberstein, Fair Pay for Home Care Workers, for more details.

23. Sonn, Ruckelshaus, and Leberstein, Fair Pay for Home Care Workers.

\section{A C K N O W L E D G M E N T S}

The author thanks Marybeth Mattingly at the Carsey Institute, Nancy Folbre at the University of MassachusettsAmherst, David Ward at the Direct Care Alliance, and Paul Sonn and Catherine Ruckelshaus at the National Employment Law Project for their thoughtful comments and suggestions; Sanjeev Sharma for research assistance; and Laurel Lloyd and Amy Sterndale for publications support.

\section{ABOUT THE AUTHOR}

Kristin Smith is a family demographer at the Carsey Institute and a research assistant professor of sociology at the University of New Hampshire (kristin.smith@unh.edu).

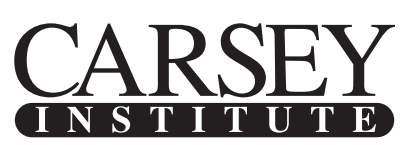

Building knowledge for families and communities

The Carsey Institute conducts policy research on vulnerable children, youth, and families and on sustainable community development. We give policy makers and practitioners timely, independent resources to effect change in their communities.

This work was supported by the Annie E. Casey Foundation, the W. K. Kellogg Foundation, the Russell Sage Foundation, and an anonymous donor.

Huddleston Hall

73 Main Street

Durham, NH 03824

(603) $862-2821$

www.carseyinstitute.unh.edu 